\title{
Investigation of Lushan earthquake ionosphere VTEC anomalies based on GPS data
}

\author{
Weiping Jiang $\cdot$ Yifang Ma $\cdot$ Hongfei Liu \\ Liansheng Deng $\cdot$ Xiaohui Zhou
}

Received: 14 June 2013/Accepted: 16 August 2013/Published online: 20 November 2013

(c) The Seismological Society of China, Institute of Geophysics, China Earthquake Administration, and Springer-Verlag Berlin Heidelberg 2013

\begin{abstract}
Vertical total electron content (VTEC) time series were obtained from 22 GPS stations near the epicenter of the Lushan earthquake. In this paper, we have adopted a sliding average method to detect and analyze anomalous VTEC associated with the earthquake. The results show that significant, negative ionosphere VTEC anomalies appeared over the 5 days before the earthquake, and on the day when earthquake occurred. The maximum value of VTEC anomalies that exceeded the lower bound reached 20 TECU. The spatial distribution of VTEC anomalies showed a conjugate structure, which shifted to the magnetic equator, and subsequently moved westwards.
\end{abstract}

Keywords Lushan earthquake - Vertical total electron content (VTEC) - Anomalous perturbation . GPS

\section{Introduction}

The first phenomenon of significant anomalous disturbance in ionosphere electron density was found over the epicenter of the 1964 Alaska earthquake several hours before the event

W. Jiang · Y. Ma $(\bowtie)$

Research Center of GNSS, Wuhan University, Wuhan 430079,

China

e-mail: csumyf2008@126.com

H. Liu

Administration of Surveying, Mapping and Geoinformation of Yunan Province, Yunan Province Administration of Surveying, Mapping and Geoinformation, Kunming 650033, China

L. Deng $\cdot$ X. Zhou

School of Geodesy and Geomatics, Wuhan University,

Wuhan 430079, China
(Leonard and Barnes 1965). Afterward, more and more investigations were suggested that ionospheric anomalies, such as variations in electron density a few days or hours before earthquakes, may take place over seismic preparation zones (Liu et al. 2004, 2010; Liu 2009; Zhang et al. 2010; Yao et al. 2012a, b). Ionospheric perturbations before earthquakes have proven to be a practical tool for short-term earthquake prediction.

In recent years, research on ionosphere total electron content (TEC) perturbations that precede earthquakes, and the mechanisms of pre-earthquake ionospheric anomalies, have become well-studied topics (Zhu et al. 2009). Since GPS data have the advantage of high temporal and spatial resolution, and high precision in TEC measurements, GPS has received much attention as a potential tool to detect ionospheric anomalies before earthquakes. Calais and Minster (1995) were the first to use GPS to detect ionospheric anomalies associated with the Northridge earthquake in 1994, and they found TEC perturbations a few minutes after the earthquake over the epicenter and around the region. Liu et al. (2004) examined ionospheric anomalies using TEC, by identifying $20 \mathrm{Ms} \geq 6.0$ earthquakes from 1999 to 2002 in Taiwan, and they found anomalous TEC disturbances from 1 to 5 days before 16 earthquakes. Wu et al. (2005) analyzed variations of VTEC before three strong earthquakes in Asia, and they found negative VTEC anomalies before these earthquakes. Many studies using TEC on ionospheric disturbances before the Wenchuan earthquake and a large 2011 earthquake in Japan showed that there were ionosphere TEC anomalies before both events (Yu et al. 2009; Liu 2009; Yao et al. 2012a; Yan et al. 2013).

This paper investigates the characteristics of temporal and spatial distribution of ionosphere VTEC before and after the Lushan earthquake in detail using data from GPS stations near the epicenter. 


\section{The Lushan earthquake}

Lushan County is located in the front margin along the southern segment of Longmenshan fault zone, and $33 \mathrm{~km}$ from Ya'an City. The Longmenshan fault zone is located along the eastern margin of the Tibetan Plateau, where earthquakes often occur. The Lushan earthquake Ms $=7.0$ originated in the Lushan County $\left(30.3^{\circ} \mathrm{N}, 103.0^{\circ} \mathrm{E}\right)$ at 00:02:00 UTC, on April 20, 2013, at $13 \mathrm{~km}$ depth. Our GPS results indicate coseismic displacements of SCTQ stations caused by the earthquake are up to $4.5,2$, and $4.3 \mathrm{~cm}$ in northern, eastern, and vertical direction (shown in Fig. 1), respectively. It is implied that there have been significant coseismic displacements caused by Lushan earthquake.

In this paper, 22 GPS stations near the epicenter of the Lushan earthquake were selected to investigate VTEC anomalies. Figure 2 shows the locations of 22 GPS stations, and the green dot shows the location of epicenter.

\section{Data processing}

\subsection{VTEC solution from GPS data}

TEC is total electron content for line of sight from the receiver on the ground to the satellite. Assuming the free electrons are concentrated in a thin shell at the height $H$ of the main electron concentration in the ionosphere, by using an elevation mapping function, TEC can be converted to
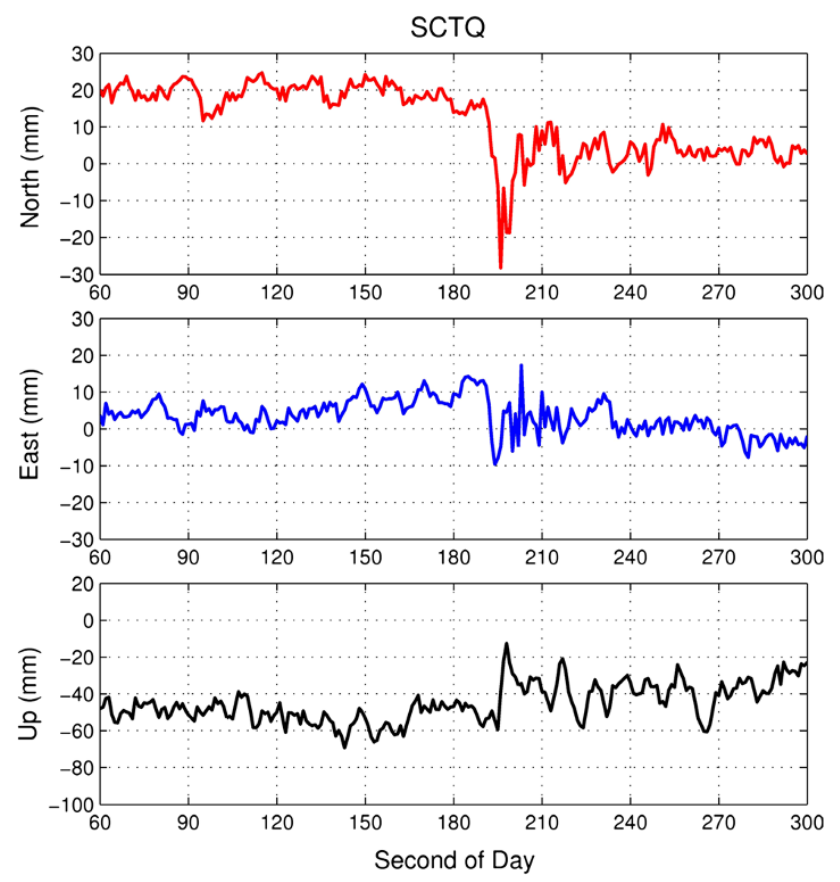

Fig. 1 Coseismic displacements of SCTQ station (time: UTC)
VTEC. $H$ is the mean ionospheric height, taken as $350 \mathrm{~km}$ in this paper, which is close to the height of maximum electron density.

The TEC is derived from the phase data using (Dautermann et al. 2007)

$$
\begin{aligned}
\mathrm{TEC}= & \left(\phi_{2}-\frac{f_{2}}{f_{1}} \phi 1+f_{2}\left(t_{\mathrm{IFB}}-t_{\mathrm{TGD}}\right)+N\right) \\
& \times \frac{c f_{1}^{2} f_{2}}{A\left(f_{1}^{2}-f_{2}^{2}\right)},
\end{aligned}
$$

where $A=40.3 \mathrm{~m}^{2} / \mathrm{s}^{2}, \phi_{1}$ and $\phi_{2}$ are carrier phases on both frequencies, $c$ is the speed of light, $N$ is integer ambiguity, $t_{\mathrm{IFB}}$ is receiver inter-frequency bias, and $t_{\mathrm{TGD}}$ is transmitter group delay. The receiver inter-frequency bias $t_{\mathrm{IFB}}$ is unknown, and is estimated from the GPS data using a least squares technique, but the transmitter group delay $t_{\mathrm{TGD}}$ is given in the navigation message of the GPS satellite and is specific to each satellite. TEC can also be computed similarly from dual-frequency pseudorange observations $\rho_{1}$ and $\rho_{2}$.

Assuming the elevation mapping function is $E_{\theta}$, rearranging (1) and substituting VTEC $=$ TEC $\times E_{\theta}$, a function of VTEC and $t_{\mathrm{IFB}}$ can be derived as

$L_{\mathrm{GU}}-f_{2} t_{\mathrm{TGD}}=\frac{K}{E_{\theta}} \mathrm{VTEC}-f_{2} t_{\mathrm{IFB}}$

with $K=\frac{A\left(f_{1}^{2}-f_{2}^{3}\right)}{c f_{1}^{2} f_{2}} ; L_{\mathrm{GU}}=\phi_{2}-\frac{f_{2}}{f_{1}} \phi_{1}+N$.

Equation (2) provides a linear relationship between observation $L_{\mathrm{GU}}$ and unknowns VTEC and $t_{\mathrm{IFB}}$ for each site. At any given measurement epoch, if at least two satellites are visible, VTEC and $t_{\mathrm{IFB}}$ can be computed using a least squares method by Eq. (2).

In this paper, the VTEC time series were calculated over each station during day of year (DOY) 90-117, adopting

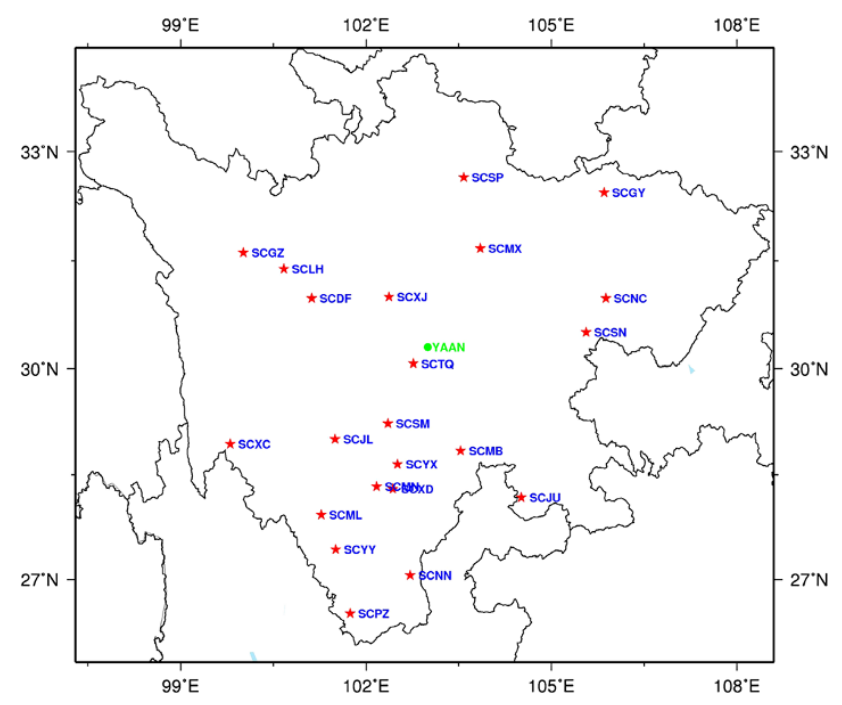

Fig. 2 Locations of epicenter and stations 
the method above and using GPS data from the 22 stations. VTEC is expressed in units of $10^{16} \mathrm{~m}^{-2}=1 \mathrm{TECU}$. All the results are expressed in UTC.

\subsection{VTEC anomaly determination}

To identify abnormal ionospheric signals, a sliding average method was adopted. The procedures can be described as follows: the first step is to choose the length of a sliding time window. We considered the previous study of Yao et al. (2012a), and that the length of the time window is limited by the natural variability of the ionosphere at longer periods, such as over seasonal timescales. We chose 10 days to be the length of a sliding time window in this paper. The second step is to choose the days to analyze. A week preceding the event, the day of the event, and a week following the event were the days analyzed in detail in this paper. The last step is to choose a background value, and upper and lower boundary values. The median $\bar{x}$ at the same time of each day during previous 10 days, and the day of the event's VTEC were computed as background value. The associated inter-quartile range (IQR) was also obtained to construct the upper bound $\bar{x}+1.5 \mathrm{IQR}$ and lower bound $\bar{x}-1.5 \mathrm{IQR}$, with 1.5IQR equaling to $2 \sigma$. If an observed VTEC exceeded either the associated upper or lower bound, an upper or lower abnormal signal was detected at a confidence level of about $95 \%$.

To avoid detecting other short lifetime perturbations caused by some other geophysics such as thunderstorms, traveling ionospheric disturbances, ionospheric bubbles, and so on, an anomalous day was considered when observed VTEC continuously exceeded the associated upper or lower bound for at least $2 \mathrm{~h}$ during a day, as was done by Liu et al. (2004).

\section{Results and analysis}

\subsection{Detection of background factors}

Solar and geomagnetic activities, and significant variations of space weather strongly affect ionospheric perturbations. So these influences should be eliminated when ionospheric anomalies are identified and correlated to an earthquake. Space weather conditions in April were examined in this paper (http://www.sepc.ac.cn/). During DOY 90-120, solar activity was at a low level except DOY 101, 102, and 112, and space weather was normal. The geomagnetic environment should also be taken into account. Therefore, geomagnetic indices were extracted (http://wdc.kugi.kyoto/). Figure 3 shows Dst and Kp indices during April 13-27 (DOY 103-107). There were geomagnetic disturbances on the DOY 114-116 (Kp > 3; Dst $<-30 \mathrm{nT})$, and the geomagnetic field was low on other days.

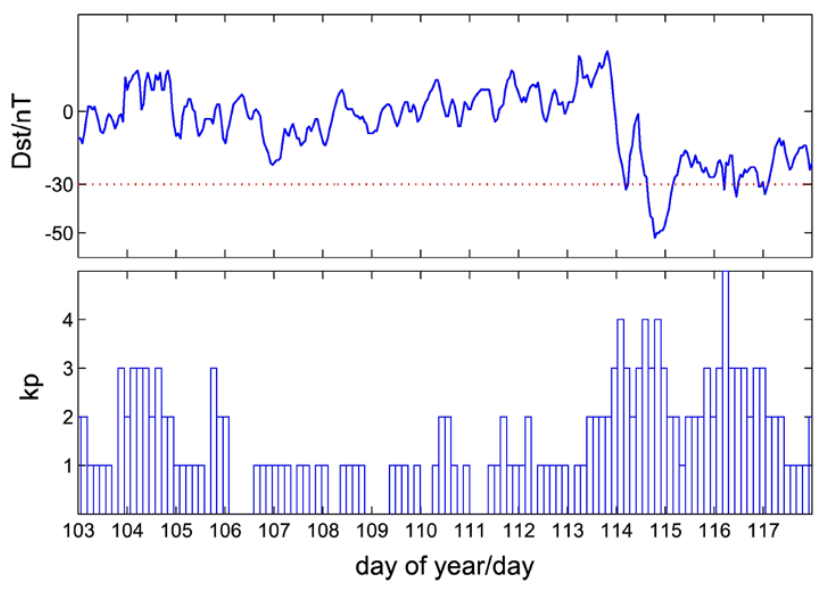

Fig. 3 Dst and Kp indices during DOY 103-107

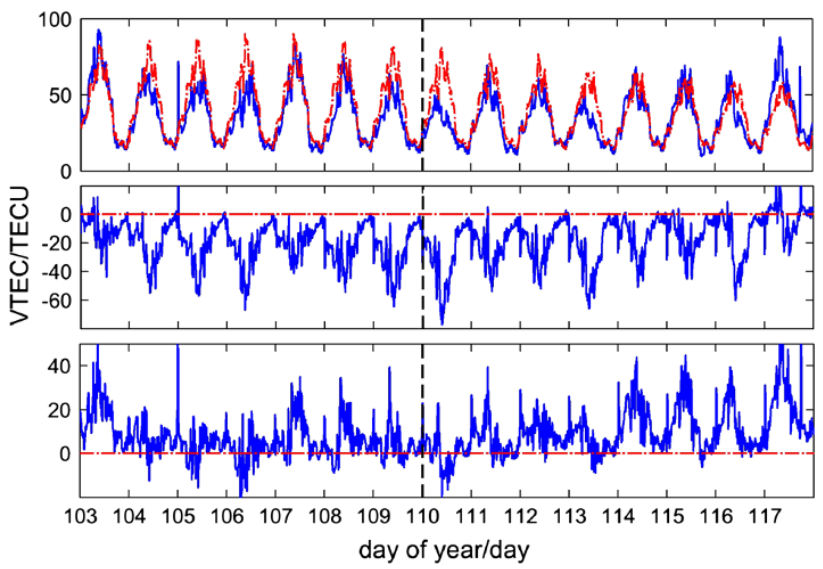

Fig. 4 VTEC variations over the SCTQ station for a week preceding and following the Lushan earthquake (black dashed line). Top figure the solid blue line shows the VTEC time series, and the red dasheddotted line shows median $\bar{x}$; middle figure the blue solid line shows VTEC $-(\bar{x}+1.5 \mathrm{IQR})$; bottom figure the blue solid line shows VTEC $-(\bar{x}-1.5 \mathrm{IQR})$. All the items are the same as those in Figs. 5 and 6

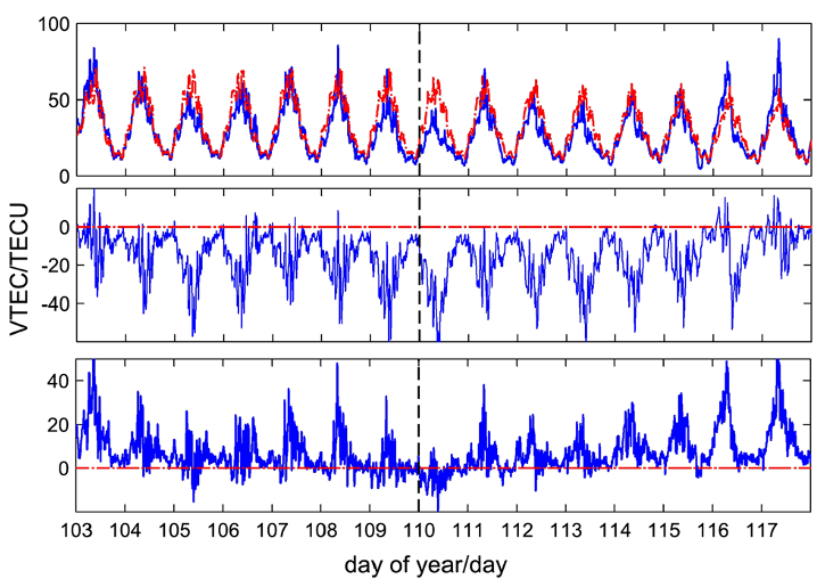

Fig. 5 VTEC variations over the SCSN station for a week preceding and following the Lushan earthquake 
4.2 Investigation of temporal distribution of VTEC anomalies

VTEC time series were calculated using observations from 22 GPS stations near the epicenter to investigate
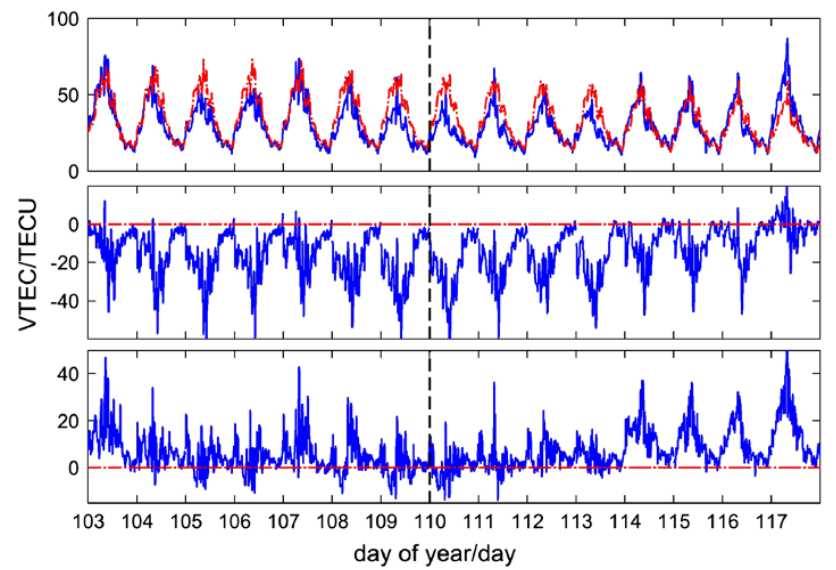

Fig. 6 VTEC variations over SCLH station for a week preceding and following the Lushan earthquake

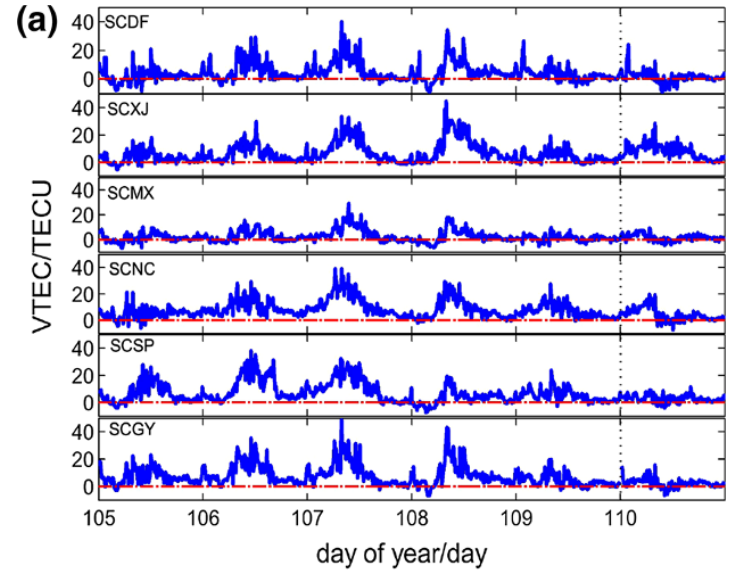

(c)

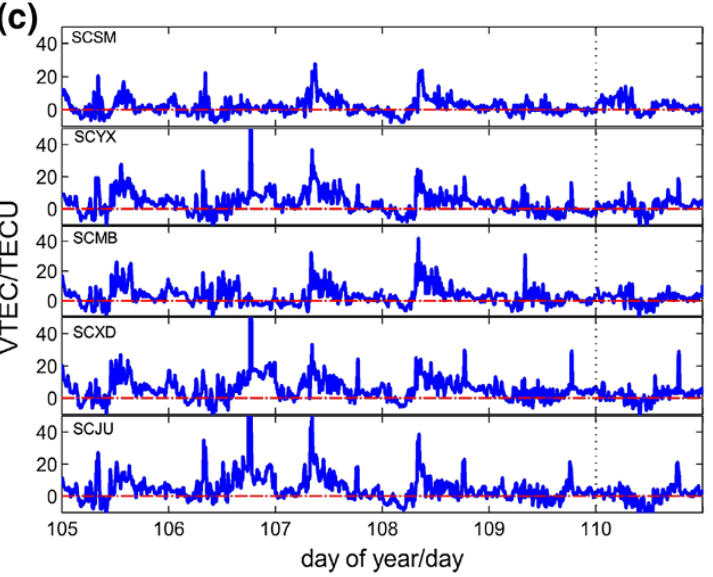

ionospheric anomalies associated with Lushan earthquake, and the time interval of the VTEC time series is $15 \mathrm{~min}$. To illustrate characteristics of ionosphere VTEC, VTEC anomalies were examined and analyzed particularly over three stations (SCTQ, SCSN, and SCLH) in this paper.

Figure 4 shows the results of VTEC anomalies over the SCTQ station which is the closest station to the epicenter during DOY 103-117 (a week preceding, the day of the event, and a week following the earthquake). Figure 4 indicates that VTEC was at a minimum on the day when the

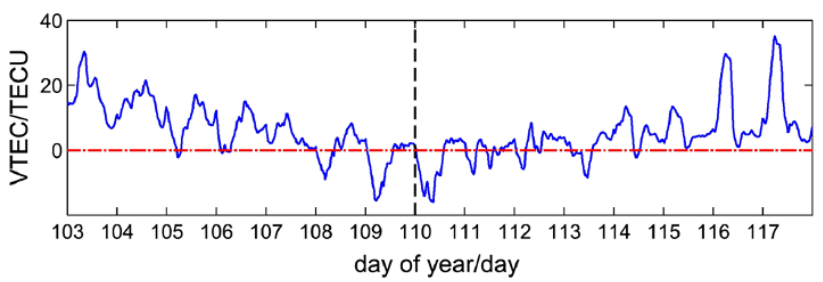

Fig. 8 VTEC variations over grid point $\left(105^{\circ} \mathrm{E}, 30^{\circ} \mathrm{N}\right)$ for a week preceding and following the Lushan earthquake (black dashed line), and the blue solid line shows VTEC $-(\bar{x}-1.5 \mathrm{IQR})$

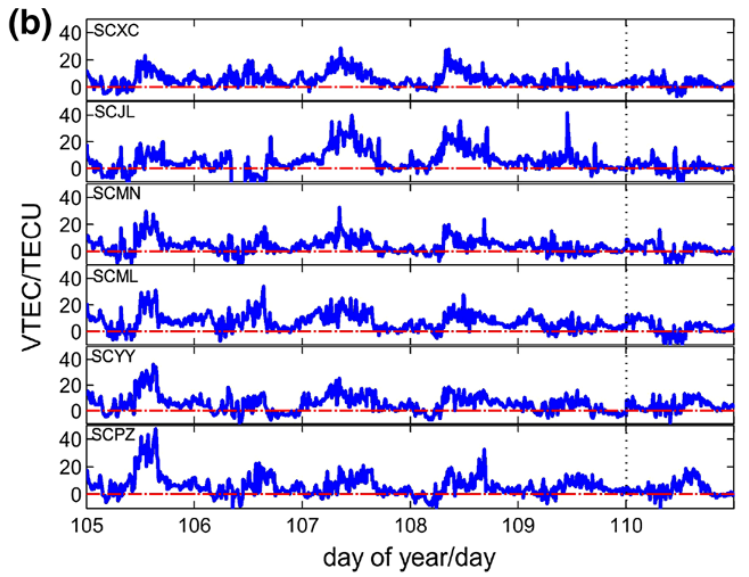

(d)

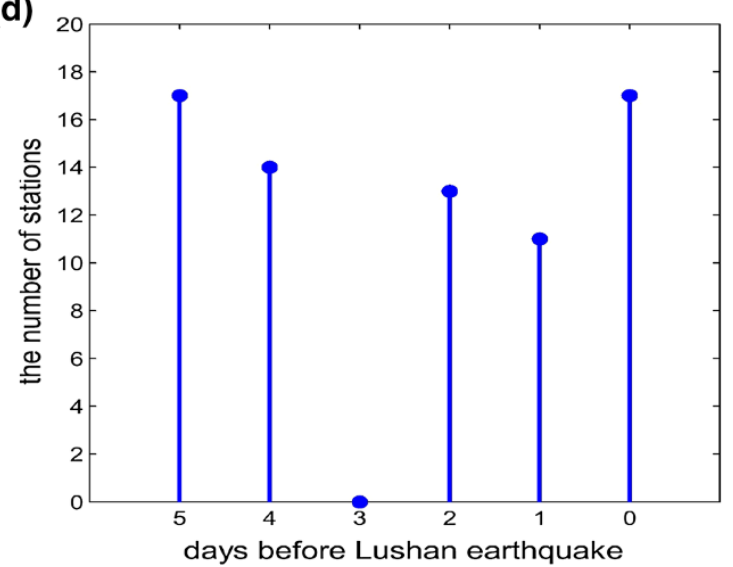

Fig. 7 a-c VTEC variations over 17 stations for 5 days preceding Lushan earthquake and the day of the event (black dotted line), and the blue solid line shows VTEC $-(\bar{x}-1.5 \mathrm{IQR})$. $\mathbf{d}$ The number of stations over which appeared VTEC anomalies was counted on each day 
earthquake occurred. Some positive anomalies appeared on the DOY 103 and 117. Considering solar and geomagnetic activities on the DOY 102 and 116, these positive anomalies were considered to be caused by solar and geomagnetic activities. VTEC tended to decrease clearly on the DOY 104-106 and 108-110. Negative anomalies appeared on the

(a)
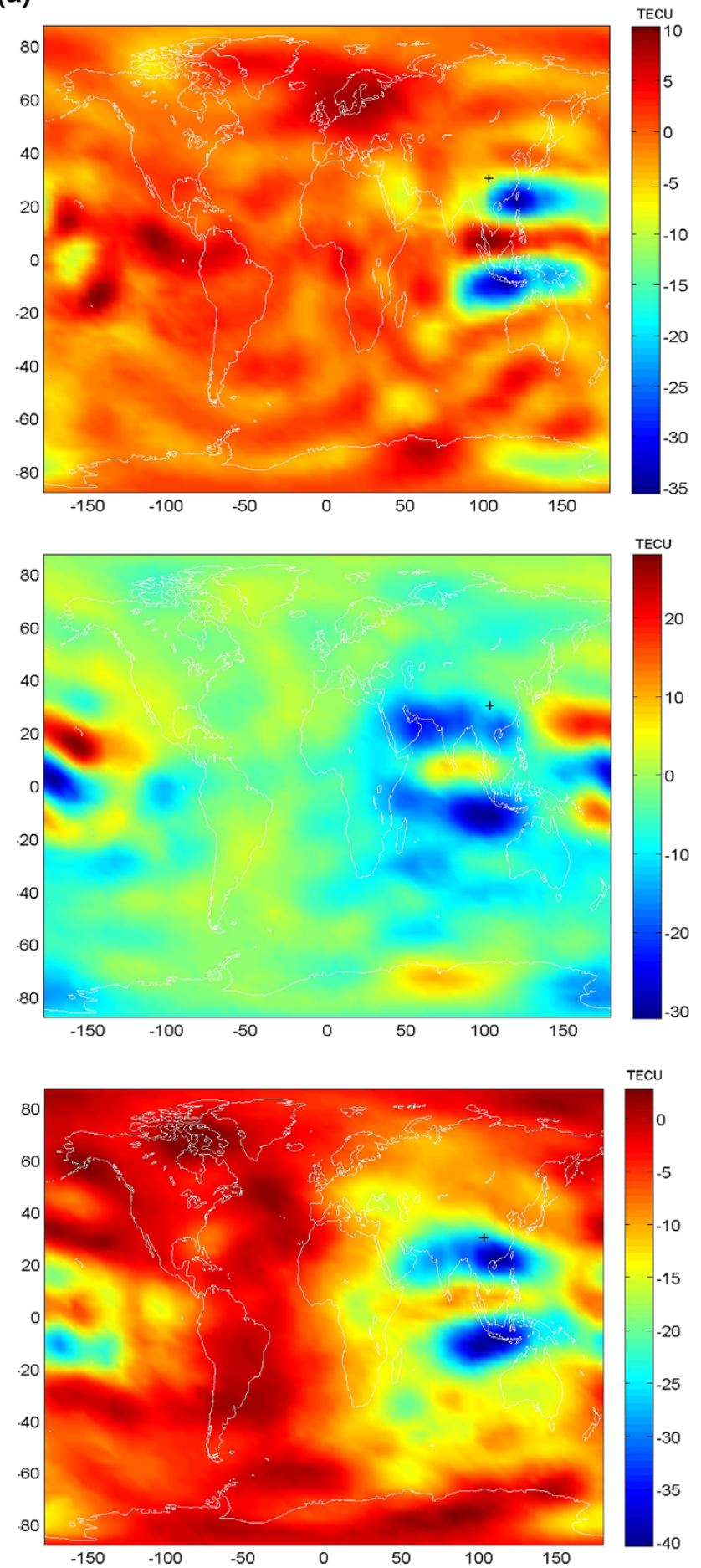

DOY $105,106,108,109$, and 110. In particular, there were more significant negative anomalies on the day when the earthquake occurred (DOY 110) with a duration of $7 \mathrm{~h}$. The maximum value exceeding the lower bound reached 20 TECU. VTEC began to increase at 16:30 UTC on the DOY 110 , and then returned to normal. Figures 5 and 6 show

(b)
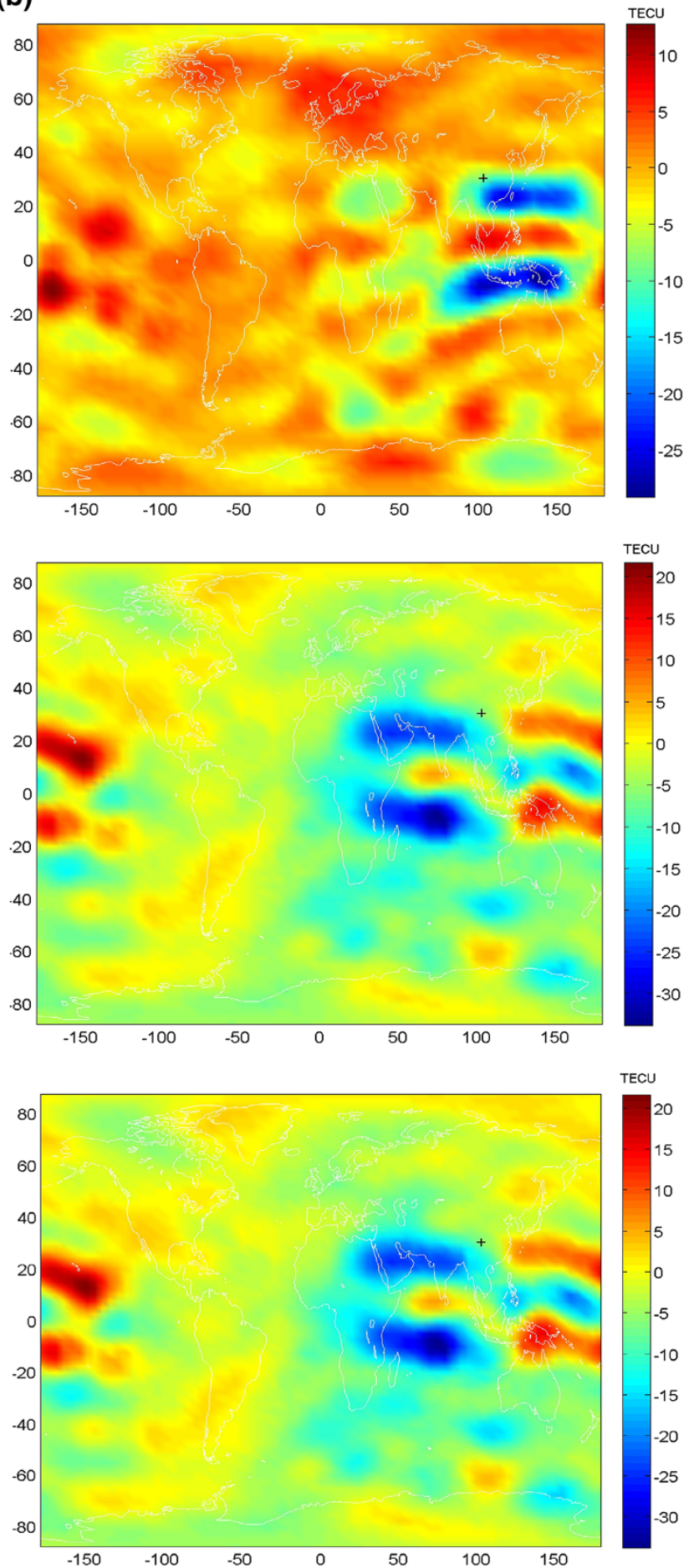

Fig. 9 Global VTEC anomalies [VTEC $-\bar{x}$ ] from 8:00 to 10:00 UTC. Top figure on the DOY 105, middle figure on the DOY 106, and bottom figure on the DOY 110. a 8:00 UTC, b 10:00 UTC. The plus sign "+" indicates epicenter 
VTEC time series over the SCSN and SCLH stations, respectively. The characteristics of VTEC anomalies were similar to those over SCTQ station, and negative anomalies were found on the DOY 105-106 and 108-110.

Considering that there are gaps in the SCGZ and SCNN data, VTEC anomalies over the other 17 stations were analyzed (see Fig. 7a-c). Combining with Figs. 4, 5, and 6, the variations of VTEC were consistent over all stations. Negative anomalies can be seen generally on the DOY 105-106 and 108-110, and the number of stations over which VTEC anomalies appeared was counted (see Fig. 7d).

In addition, the global ionospheric map (GIM) provided by International Global Navigation Satellite System (GNSS) Service (IGS) was used during the same period for the same analysis. GIM is obtained using GNSS data from hundreds of IGS stations with a resolution of $2 \mathrm{~h}$ (time), $5^{\circ}$ (longitude), and $2.5^{\circ}$ (latitude), respectively. Because of low temporal and spatial resolution of the GIM, the overall trend of VTEC variations was examined over the epicenter using the GIM in this paper. Figure 8 shows VTEC $-(\bar{x}-$ 1.5IQR) over the nearest grid point $\left(105^{\circ} \mathrm{E}, 30^{\circ} \mathrm{N}\right)$ from the epicenter. It is obvious that the VTEC decreased on the DOY $105-106$ and 108-110. There were negative anomalies on the DOY 108-110. The results are consistent with the VTEC analysis above, which affirms the reliability of the above calculation and the analysis of VTEC.

Taking into account the analysis of background factors, negative ionosphere VTEC anomalies on DOY 105-106 and $108-110$ are likely to be closely associated with the Lushan earthquake.

\subsection{Investigation on the spatial distribution of VTEC anomalies}

The above analysis mainly focused on VTEC time series at a single station. Considering the locations and results of all stations, the spatial distribution of VTEC anomalies from the local network can be concluded as follows: the VTEC anomalies are more significant at the stations which are closer to the epicenter. Moreover, the variations of VTEC over the stations located in the south of the epicenter were more significant.

There were more significant negative anomalies associated with the earthquake on the DOY 105-106 and 110 from the above analysis. Therefore, the global spatial distribution of ionospheric anomalies was investigated on the DOY 105-106 and 110 in this section. Figure 9 shows global abnormal VTEC value [VTEC $-\bar{x}$ ] maps from 8:00 to $10: 00$ UTC on the DOY $105-106$ and 110 , with a time interval of $2 \mathrm{~h}$. The spatial distribution and variations of ionospheric anomalies can be seen clearly. The affected area ranged from $15^{\circ} \mathrm{N}$ to $30^{\circ} \mathrm{N}$ in latitude, with a maximum longitude span of $55^{\circ}$. The corresponding ionospheric effects could be observed in the magnetically conjugate region. The location of the maximum of the affected area in the ionosphere did not coincide with the vertical projection of the epicenter, but was instead to the south and closer to equator, which is further westwards, and shifted toward the magnetic equator. There were no significant or similar ionosphere VTEC anomalies in the rest of the world at this time. Ionospheric anomalies caused by the space environment generally perform over a wider geographic range. However, observed ionospheric anomalies appeared only near the epicenter, with a comparatively long duration. This provides further evidence that the ionospheric anomalies observed on the DOY 105-106 and 110 were associated with the Lushan earthquake.

\section{Conclusions}

Coseismic displacements caused by the Lushan earthquake are apparent along the horizontal and vertical directions, and the largest amplitudes are about 5 and $4.3 \mathrm{~cm}$, respectively. This paper focused on ionosphere VTEC anomalies associated with Lushan earthquake. The main conclusions can be enumerated as follows:

(1) It is obvious that severe ionosphere VTEC negative anomalies occurred over 5 days preceding the earthquake, as well as on the day when the earthquake occurred, and were associated with the earthquake closely with maximum duration of $7 \mathrm{~h}$. The maximum value exceeding the lower bound reached 20 TECU.

(2) The VTEC decreased over the 5 days, before the earthquake, and on the day when the event occurred, over the nearest grid point of GIM from the epicenter.

(3) The location of the affected area of the ionospheric anomalies was not coincident with the vertical projection of the epicenter, but was to its south and closer to equator, which is shifted toward the magnetic equator and moved westwards. The affected area reached $15^{\circ}$ in latitude and $30^{\circ}-55^{\circ}$ in longitude. The corresponding ionospheric effects could be observed in the magnetically conjugate region. Moreover, there were no significant or similar ionosphere VTEC anomalies in the rest of the world at this time.

The statistical studies (Pulinets et al. 2003, 2010; Pulinets 2012) indicated that ionospheric precursors appeared on average 5 days before an earthquake. The location of the maximum of the affected area in the ionosphere does not coincide with the vertical projection of the epicenter. The corresponding ionospheric effects can be observed in 
the magnetically conjugated region by the middle latitude earthquake. The results in this paper are similar to those presented above, which are helpful for the investigation of ionospheric anomalies preceding earthquakes.

Acknowledgments This research was supported by the National Natural Science Foundation of China (41074022), the National 863 Program of China (2012AA12A209) and Open Research Fund Program of Geospace Environment and Geodesy (LOGEG), Ministry of Education, China (No. 1202012).

\section{References}

Calais E, Minster JB (1995) GPS detection of ionospheric perturbations following the January 17, 1994, Northridge earthquake. Geophys Res Lett 22:1045-1048

Dautermann T, Calais E, Haase J, Garrison J (2007) Investigation of ionospheric electron content variations before earthquakes in southern California, 2003-2004. J Geophys Res Atmos 112: B02106

Leonard RS, Barnes RA (1965) Observation of ionospheric disturbances following the Alaska earthquake. J Geophys Res 70(5): $1250-1253$

Liu JY et al (2009) Seismoionospheric GPS total electron content anomalies observed before the 12 May 2008 Mw7.9 Wenchuan earthquake. J Geophys Res Space Phys (1978-2012) 114(A4): A04320

Liu JY, Chuo YJ, Shan SJ et al (2004) Pre-earthquake ionospheric anomalies registered by continuous GPS TEC measurements. Ann Geophys 22:1585-1593

Liu JY, Chen YI, Chen CH, Hattori K (2010) Temporal and spatial precursors in the ionospheric global positioning system (GPS) total electron content observed before the 26 December 2004
M9.3 Sumatra-Andaman earthquake. J Geophys Res Atmos 115:09312

Pulinets S (2012) Low-latitude atmosphere-ionosphere effects initiated by strong earthquakes preparation process. Int $\mathrm{J}$ Geophys. doi: $10.1155 / 2012 / 131842$

Pulinets SA, Legen'ka AD, Gaivoronskaya TV et al (2003) Main phenomenological features of ionospheric precursors of strong earthquakes. J Atmos Solar Terr Phys 65(16):1337-1347

Pulinets SA, Bondur VG, Tsidilina MN et al (2010) Verification of the concept of seismoionospheric coupling under quiet heliogeomagnetic conditions, using the Wenchuan (China) earthquake of May 12, 2008, as an example. Geomagn Aeron 50(2): 231-242

Wu Y, Qiao XJ, Zhou YY (2005) Preseismic ionospheric TEC anomaly detected by ground-based GPS. J Geodesy Geodyn 25(2):36-40 (in Chinese with English abstract)

Yan XX, Shan XJ, Cao JB et al (2013) Preliminary study of the seimoionospheric perturbation before Tohoku-oki $\mathrm{Mw} 9.0$ earthquake. Prog Geophys 28(1):0155-0164

Yao YB, Chen P, Wu H et al (2012a) Analysis of ionospheric anomalies before the 2011 Mw9.0 Japan earthquake. Chin Sci Bull 57:500-510

Yao YB, Chen P, Zhang S et al (2012b) Analysis of pre-earthquake ionospheric anomalies before the global $\mathrm{M}=7.0+$ earthquakes in 2010. Nat Hazards Earth Syst Sci 12(3):575-585

Yu T, Mao T, Wang YG et al (2009) Study of the ionospheric anomaly before the Wenchuan earthquake. Chin Sci Bull 54(6):1086-1092 (in Chinese with English abstract)

Zhang XM, Liu J, Shen XH et al (2010) Ionospheric perturbations associated with the M8.6 Sumatra earthquake on 28 March 2005. Chin J Geophys 53(3):567-575 (in Chinese with English abstract)

Zhu FY, Wu Y, Lin J et al (2009) Anomalous response of ionospheric VTEC before the Wenchuan earthquake. Earthq Sci 31(2): 180-187 (in Chinese with English abstract) 